\title{
ПРОГРАММНЫЙ КОМПЛЕКС ДЛЯ ВЕСОВ ГЕРКУЛЕС
}

\section{SOFTPAD WARE FOR HERCULES WEIGHT-METER}

\section{K. Voloshinovsky}

Summary. Wieghtmeter - not only a means tool for mass of substance outlay account taking into or not an additional snap around rigging, but the mass of let pass devices and machines.

Modern precision-exactness and ergonomics requirements appeared to be quite wider. Primary weight transformer-converter equipped with modern digital data transition ports \& requests, allows to develop software for efficient operative short-discrete \& extra continuous mode. For being applied to differentiate data stream by the operators, account items \& etc.

The article represents software developing example for Hercules weightmeter manufactured \& delivered with CAS-center (Moscow/Russia) in MSVisual Studio TeamSystem 2008 to accent and a little-bit correct weight-meter in proceeding mode in automated \& handmade modes for IBM PC compatible CIL-integrated in MSVisual Studio.

Keywords: Wieght-meter, CAS Hercules, software, database attributing

\author{
Волошиновский Кирилл Иванович \\ К.т.н., дочент, Национальный исследовательских \\ технологический университет МИСиС \\ gas7dev@gmail.com
}

Аннотация. Весы — не только средство учета массового расхода рабочего тела или субстанции сучетом её дополнительной оснастки или без, но и массы пропускаемых и выпускаемых приборов и машин. Современные требования по точности и эргономике растут. Первичные преобразователи весов оснащены современными цифровыми портами передачи данных и запроСOB, что позволяет проводить разработку программного обеспечения для оперативного кратковременного и непрерывного режима. Для дифференцирования потока данных по операторам, наименованиям учитываемых позиций и т.д. В статье рассматривается пример разработки программного обеспечения для весов Геркулес производства и поставки CAS-Центр (Москва/Россия) в среде MSVisual Studio TeamSystem 2008. Подчеркнуть или подкорректировать работу весов в автоматическом и ручном режиме можно обратным пакетом управления от программы для ЭВМ совместимой на уровне промежуточного кода (CIL).

Ключевые слова: Весы, Геркулес, программное обеспечение, атрибутизация баз данных.

Работа с весами в неатрибутированном режиме при непрерывной эксплуатации также требует дополнительной систематизации, хотя размер базы данных несколько меньше. Для сравнения в учете газа размер часовой базы данных за 5 лет составляет порядка 76-78МБайт[4] (если подбирать все базы пришедшие с прибора из часовых показаний с емкостью архива 2 месяца), что требует периодического сжатия базы данных. Если весы будут накапливать не по одной записи в среднем каждый час, то база данных может расти существенно.

Первичный преобразователь весов обычно универсальный, как в данном случае и позволяет подключить чувствительный элемент (штангу) с унифицированным интерфейсом. Таким образом, можно подключить к первичному преобразователю весы как малометражные, так и крупные: паллетные или платформенные.

Первичный преобразователь весов предусматривает обычно подключение через порт com232, который можно адаптировать для USB или порт Ethernet RJ45, что позволяет включить весы в офисную сеть, что требует разработки дополнительного программного обеспечения (ПО). Чтобы включить весы в промышленную сеть 


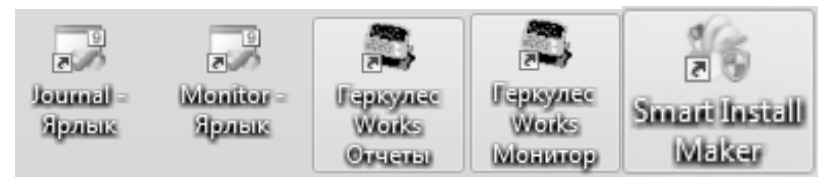

Рис. 1. Ярлыки программного комплекса весов

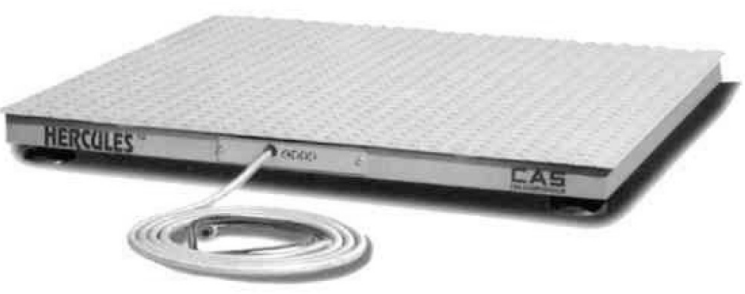

Рис. 2. Платформенные весы

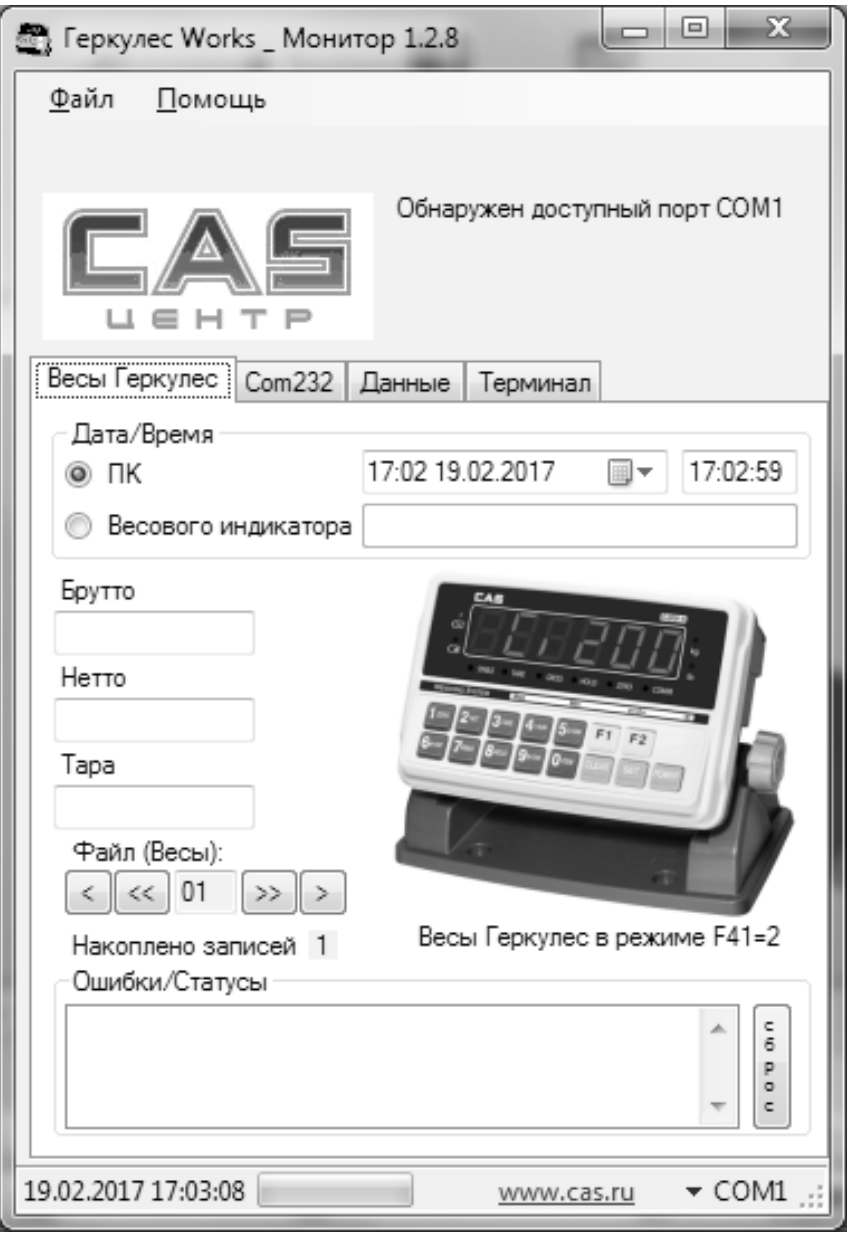

Рис. 3. Вид главного окна программы циклического опроса

достаточно настроить Com-port через протокол UDPEthernet.

Программа циклического опроса весов Геркулес Works Монитор[1]:

Также как и в учете газа, т.е. в учете объемного расхода, при массовом расходе опрос преобразователя ведется в дуплексном или полудуплексном режиме. В процессе бесконечного рабочего цикла программа следит за байтами поступающими через последовательный
Com-port с применением элемента управления SerialPort по сути в терминальном режиме.

В главном окне отображаются параметры последнего взвешивания с учетом тары и без. Предусмотрено два режима работы: расширенный и обычный. В расширенном режиме требуется ключ vesy.key и vesy.ext.

При первом запуске в пункте «Помощь \вести код и номер весов» вводятся: [Код] и [Номер весов], которые хранится в файле vesy.ext. 


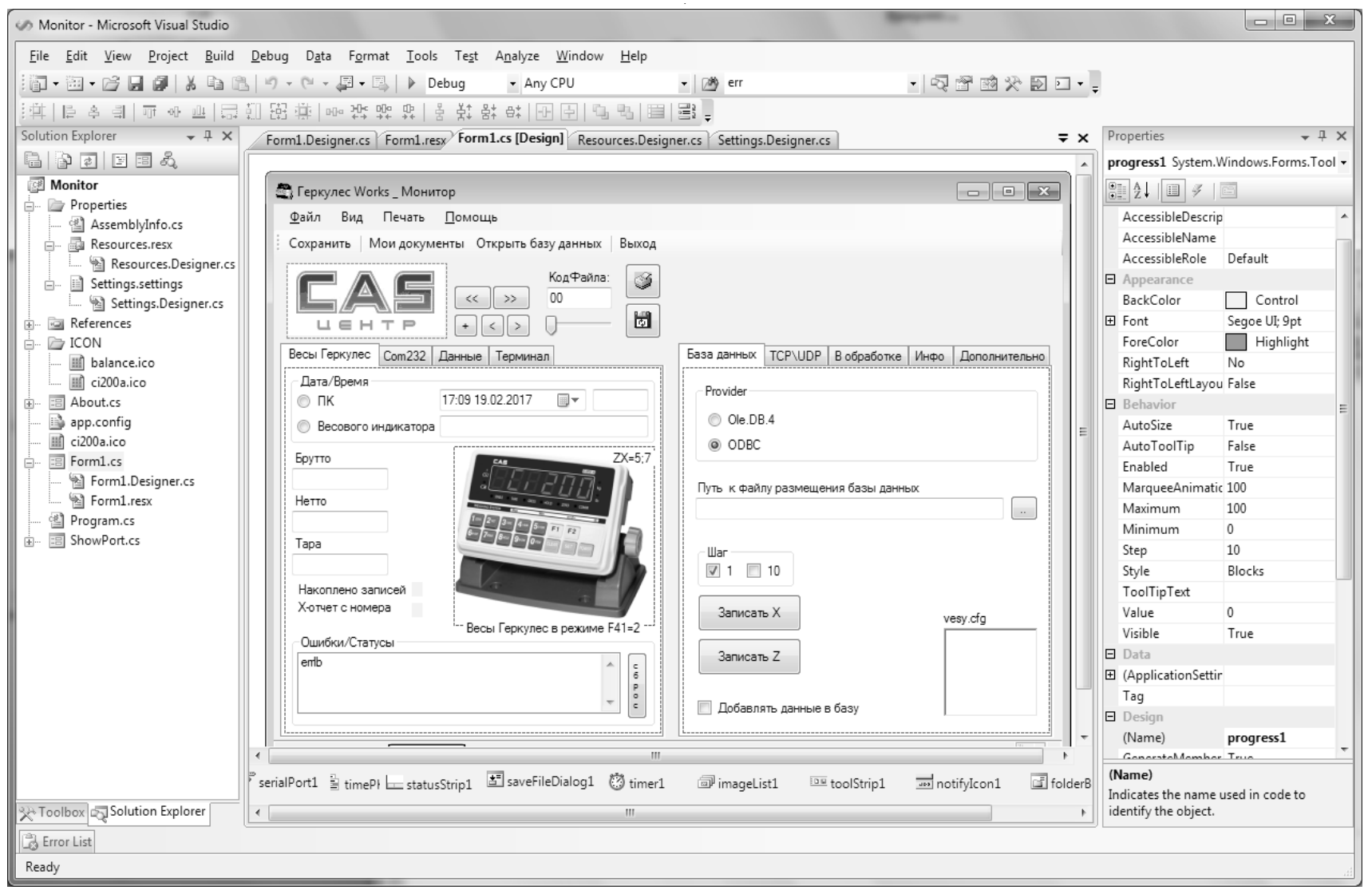

Рис. 4. Главное окно программы в расширенном режиме в процессе разработки

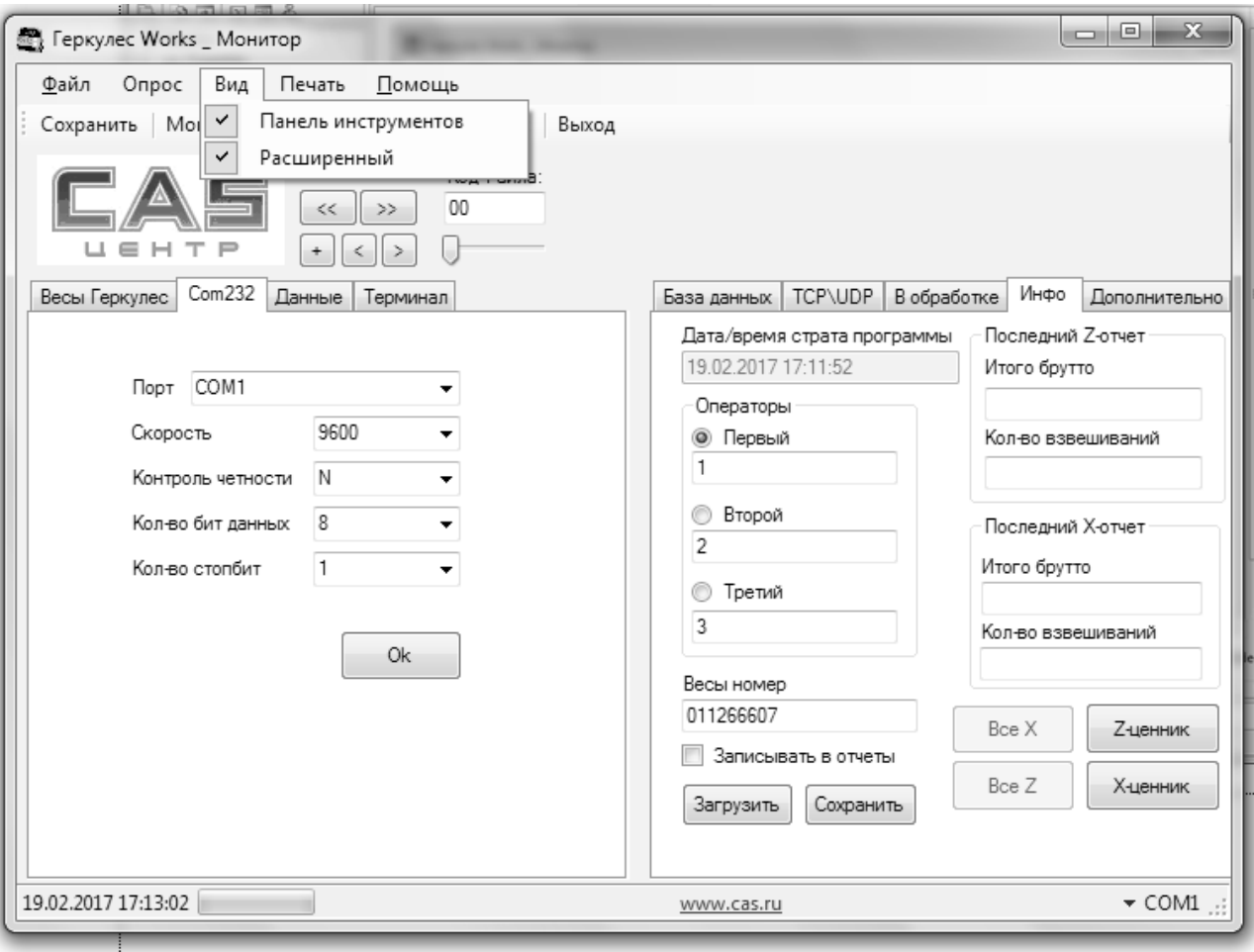

Рис. 5. Главное окно: вкладки настройки Com-порта и привязки к операторам 
Таблица 1. Пример состава файла отчета

\begin{tabular}{|c|c|c|c|c|c|c|c|c|c|c|}
\hline \multicolumn{7}{|c|}{ 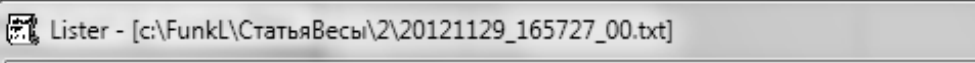 } & \multicolumn{3}{|l|}{ 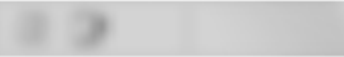 } & \begin{tabular}{|l|l|l|}
$口$ & 回 & $X$ \\
\end{tabular} \\
\hline Файл Правка & ид Справка & & & & & & & & & $100 \%$ \\
\hline \multicolumn{2}{|c|}{ Дата } & Брутто & Tapa & Нетто & & & Номер в & \multicolumn{2}{|l|}{ Взвешивания } & Примечание (Код \\
\hline ошибки ) & & & & & & & & & & \\
\hline 2002.3 .29 & 0:50 & & & b & & b & & o & & 0001 \\
\hline 2002.3 .29 & $0: 50$ & & & g & & b & & b & & 0002 \\
\hline 2002.3 .29 & $0: 50$ & & & g & & g & & 6 & & 0053 \\
\hline 2002.3 .29 & 0:50 & & & b & B & b & 1 & & 3 & SUB TOTAL \\
\hline 2002.3 .29 & $0: 50$ & & & g & & 0 & & o & & 0001 \\
\hline 2002.3 .29 & $0: 50$ & & & g & & g & & g & & 0002 \\
\hline 2002.3 .29 & 0:50 & & & g & & b & & g & & 0003 \\
\hline $2602 \cdot 3.29$ & $0: 51$ & & & b & 0 & 0 & 1 & & 3 & GRAND TOTAL \\
\hline
\end{tabular}

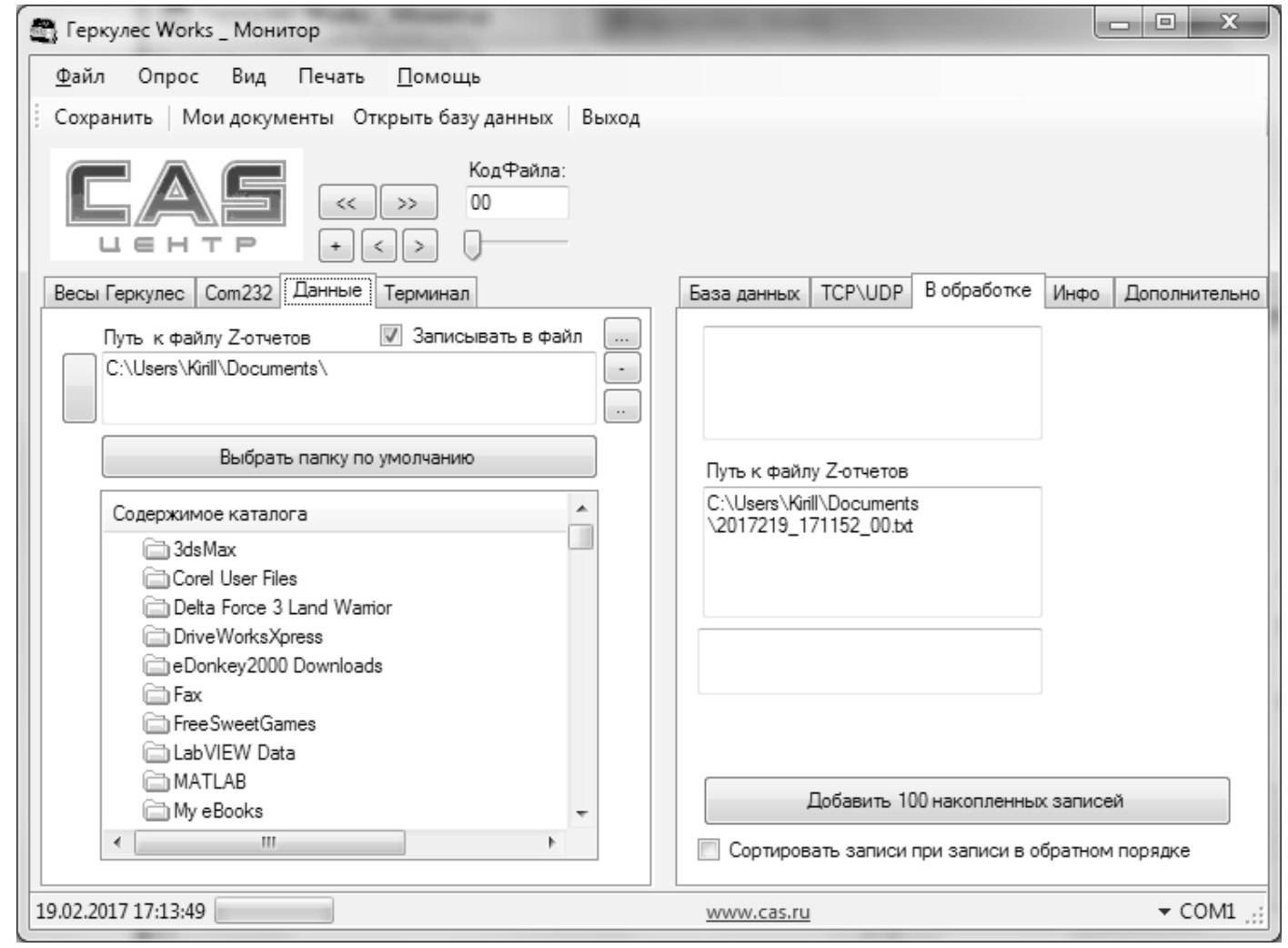

Рис. 6. Главное окно: вкладки сохранения и обработки отчетов

В расширенном режиме предусмотрен выбор оператора в начале процесса взвешивания.

Окно настройки параметров последовательного порта приводится на рис. 5. Определяется скорость обмена, контроль четности, битность передачи, количество контрольных бит.

Запись результатов взвешивания в файл с накоплением можно отключить. Информация записывается в виде
Z-отчетов и X-отчетов в формате, заложенном в первичный преобразователь.

Сетевое подключение без использования виртуального UDP\COM драйвера можно предположить по протоколу TCP-IP.

Файлы Z-отчетов автоматически записываются в папку «Мои документы», что связано с политикой администрирования, если для записи оказывается только такая 


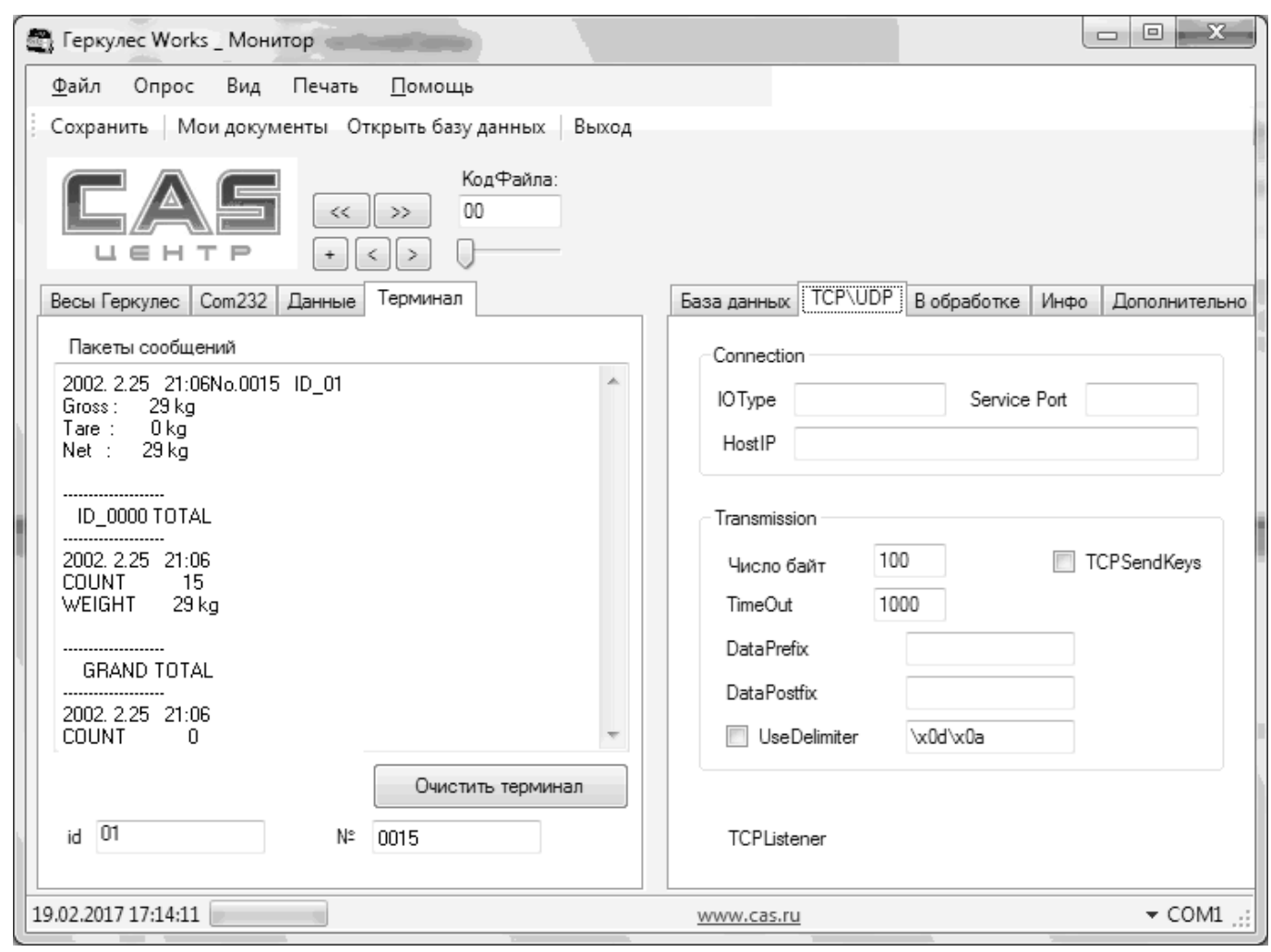

Рис. 7. Главное окно: Терминал и сетевые настройки

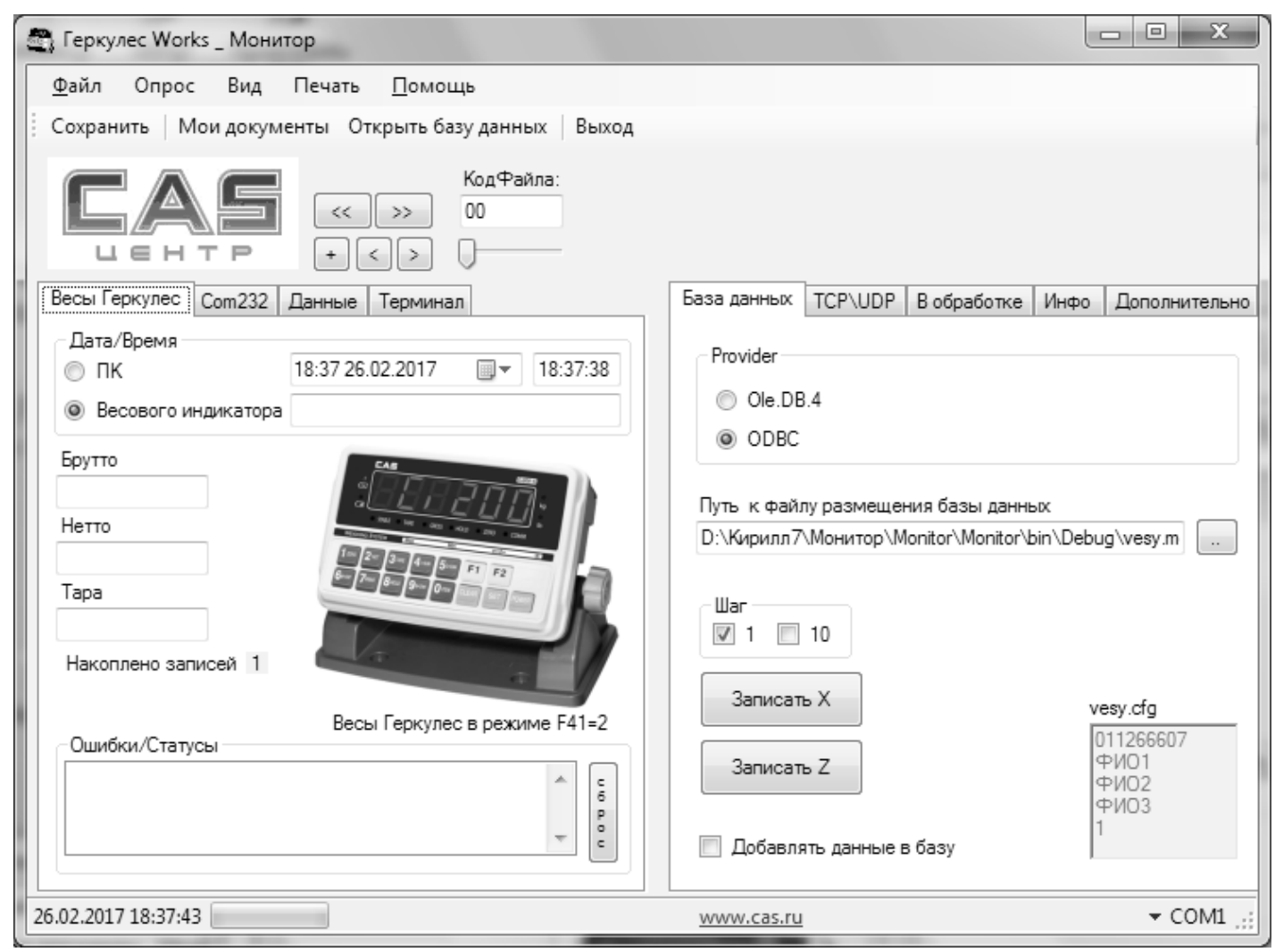

Рис. 8. Главное окно программы в расширенном режиме 


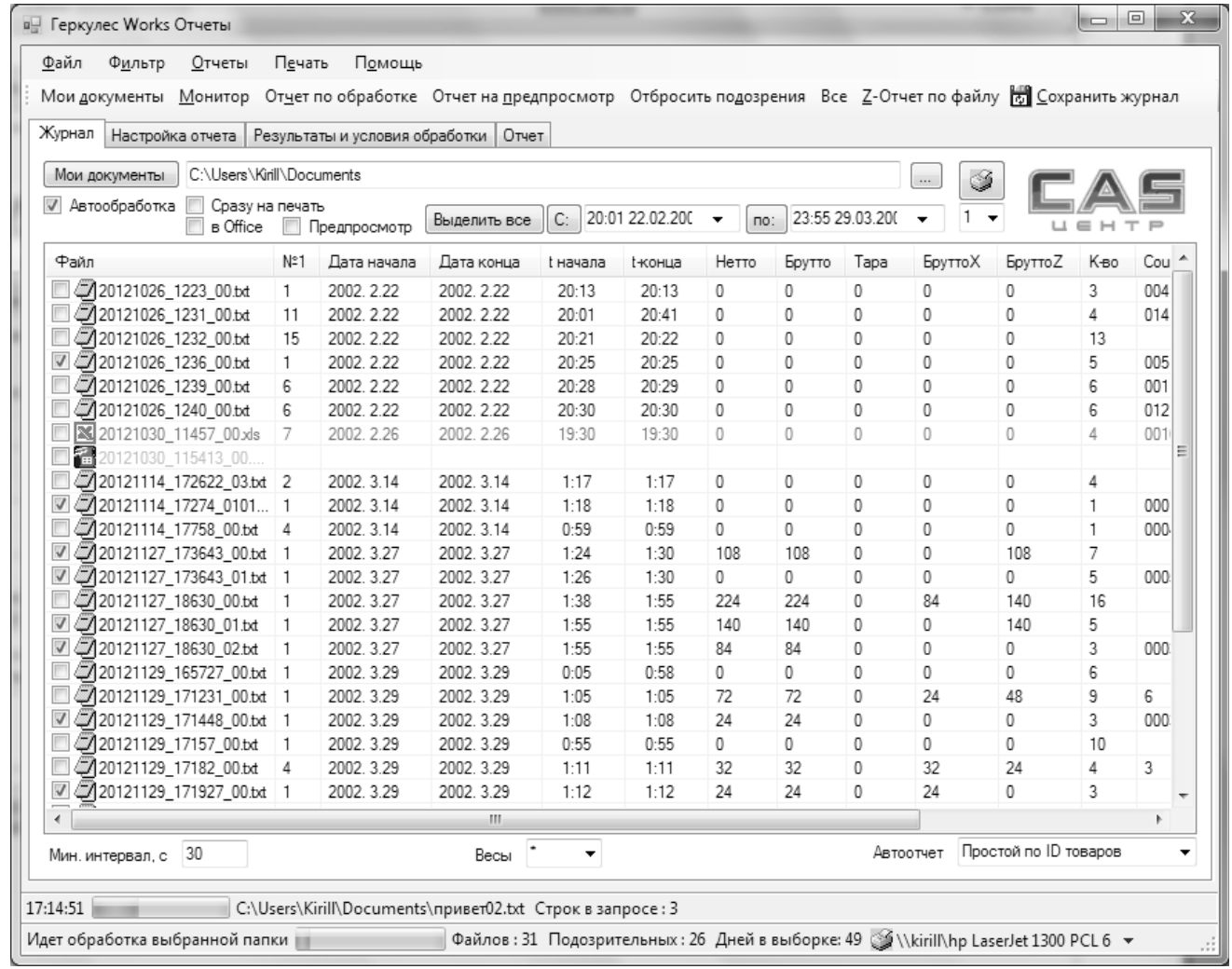

Рис. 9. Главное окно программы анализа и отбраковки пакетов

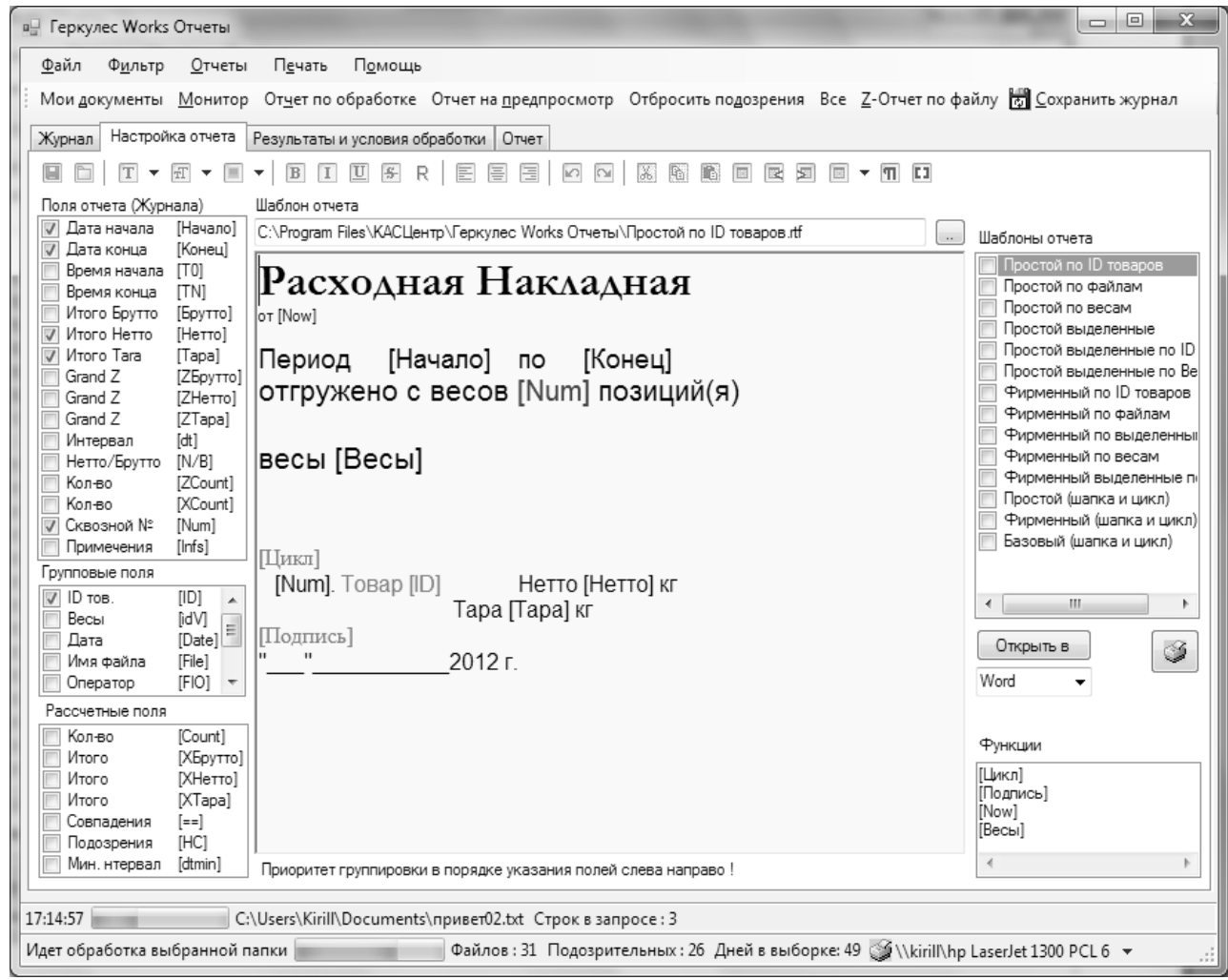

Рис. 10. Настройка шаблона в программе Геркулес Works Отчеты 


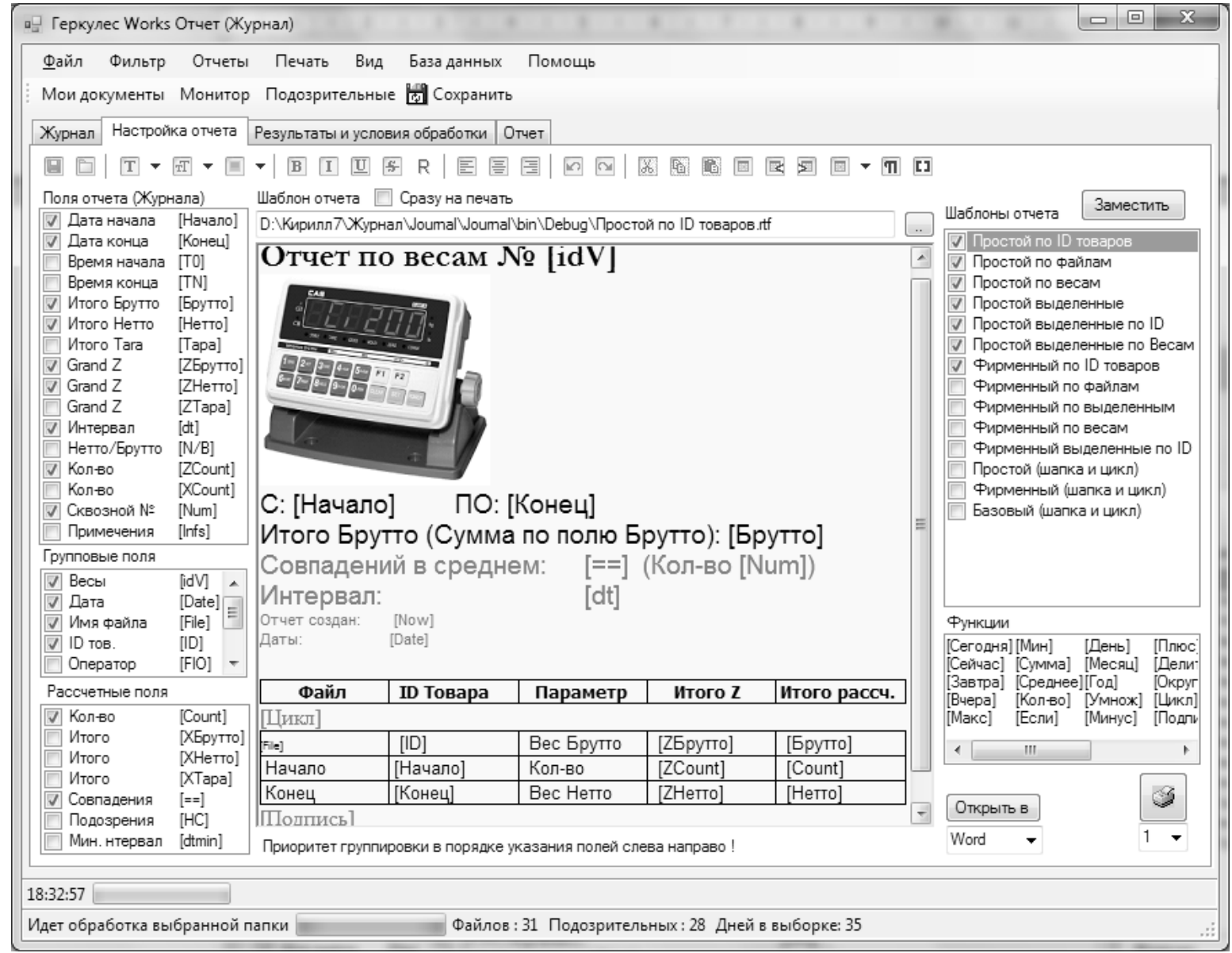

Рис. 11. Отчет в формате RTF с циклическим заполнением таблицы

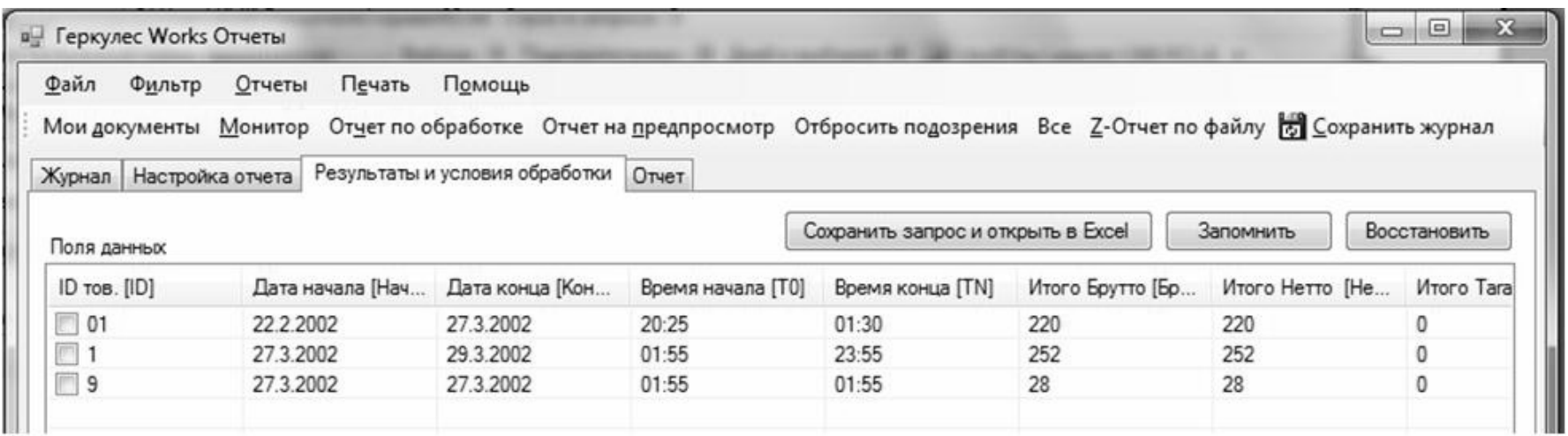

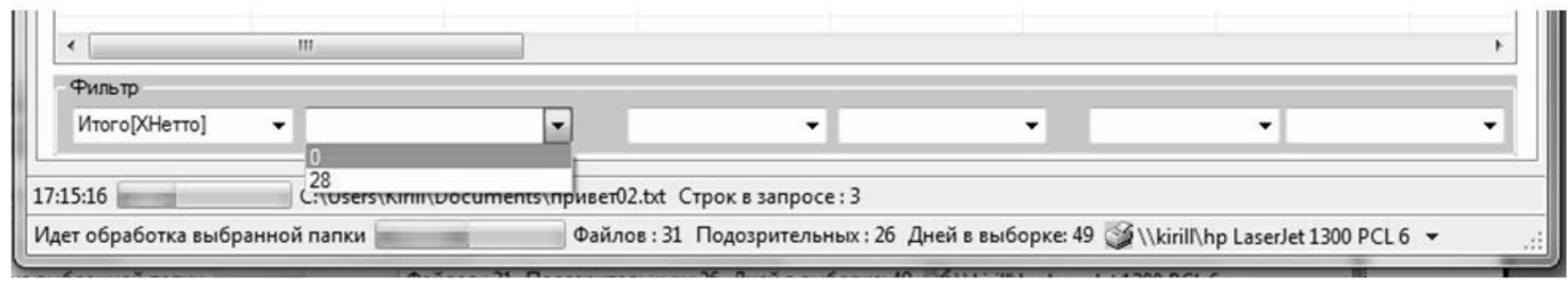

Рис. 12. Результаты обработки для затребованных полей из шаблона в программе Геркулес Works Отчеты 


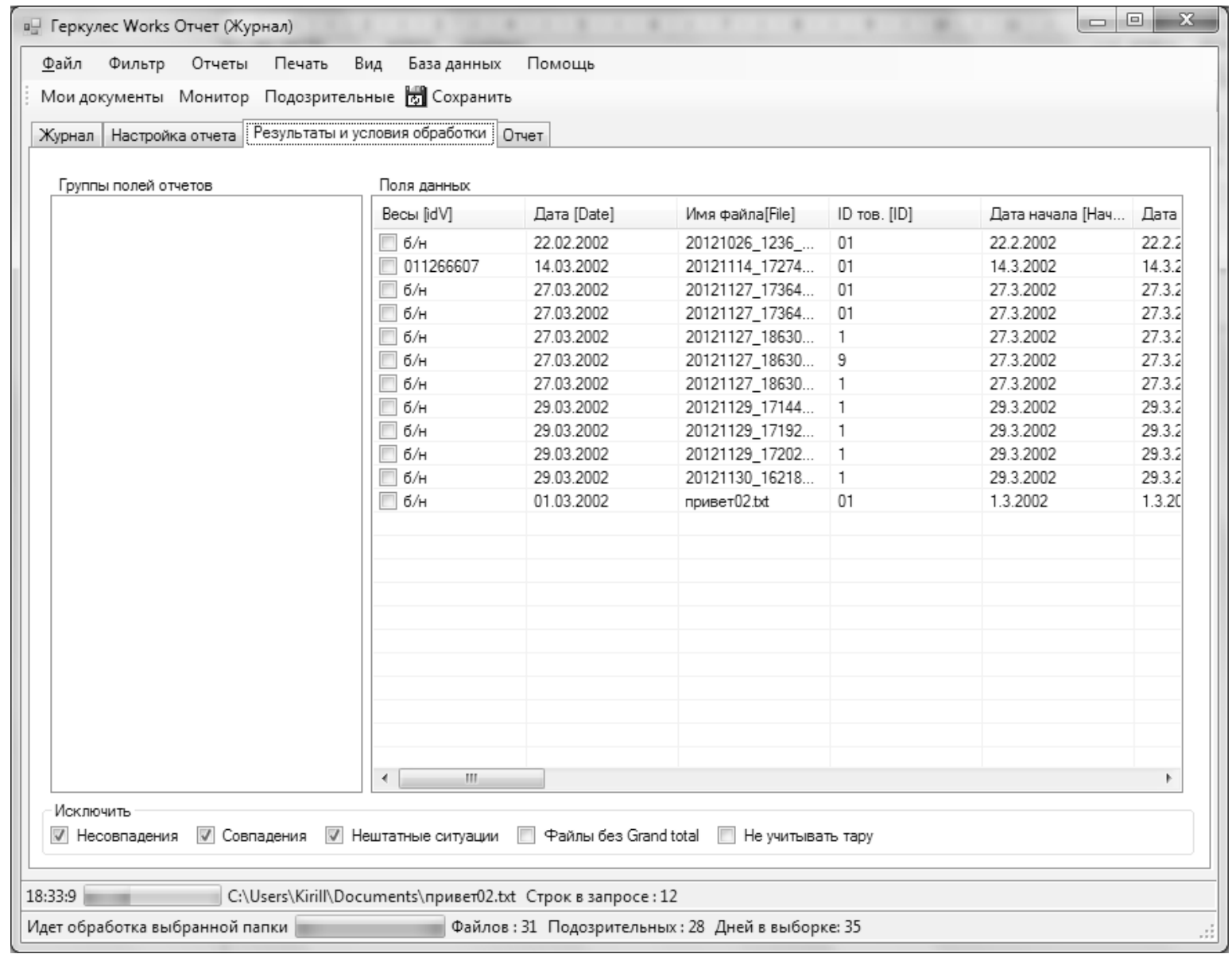

Рис. 13. Предварительный просмотр результатов обработки

папка пользователя. Последний порт из списка выбирается автоматически в расчете на последнюю установку драйвера USB/Com преобразователя. Имя файла создается программой автоматически, включается дата создания файла и время создания файла, а номер припасовывается в соответствии с полем КодФайла, который можно перебирать кнопками перехода.

При нажатии клавиш I-Sum (4) и Print (7) приходит Sub-total. При нажатии клавиш G-Sum (5) и Print (7) приходит Grand-total. При нажатии Grand-total в файл добавляется строка с итогом и файл автоматически закрывается, после чего программа переходит на новый код, а кнопку перехода нажимает сама. Запись происходит с кодировкой ANSI UTF-8. Для программы анализа отчетов не важно в каком текстовом формате «лежит» отчет, анализ производится только для числовых полей.

В состав пакета файлов программы включен файл vesy.mdb, который доступен через драйвер-provider, если на компьютере установлена MSNetFrameWork версии не ниже 2.0 для платформы х86, и версии 3.0 для платформы х64. Для ввода ID товара можно потенциально использовать сканер штрих-кода, подключенный к весам.

Программа анализа пакетов циклического опроса Гекулес Works Отчеты (Журнал)[3]. В процессе анализа возникает потребность отбросить лишние данные: результаты неудачных взвешиваний, излишние дубли, идентичные файлы и др.

Можно выявить много разных критериев для анализа, но важно сделать вывод о емкости оконечной сводки для z- и х- отчетов, поэтому в строке статуса отображается глубина охвата совокупности текстовых файлов протоколов, если файл сохранен для xls или csv, oH выводится со своей пиктограммой и подсвечивается другим цветом. Подозрительные файлы не помечаются checkbox-oм, а журнал выводит полный список с учетом фильтра и заданного условия отбора.

Настройка генератора отчетов производится во вкладке настройка отчета: задается «шапка» шаблона с оформлением без разделителя раздела; область 


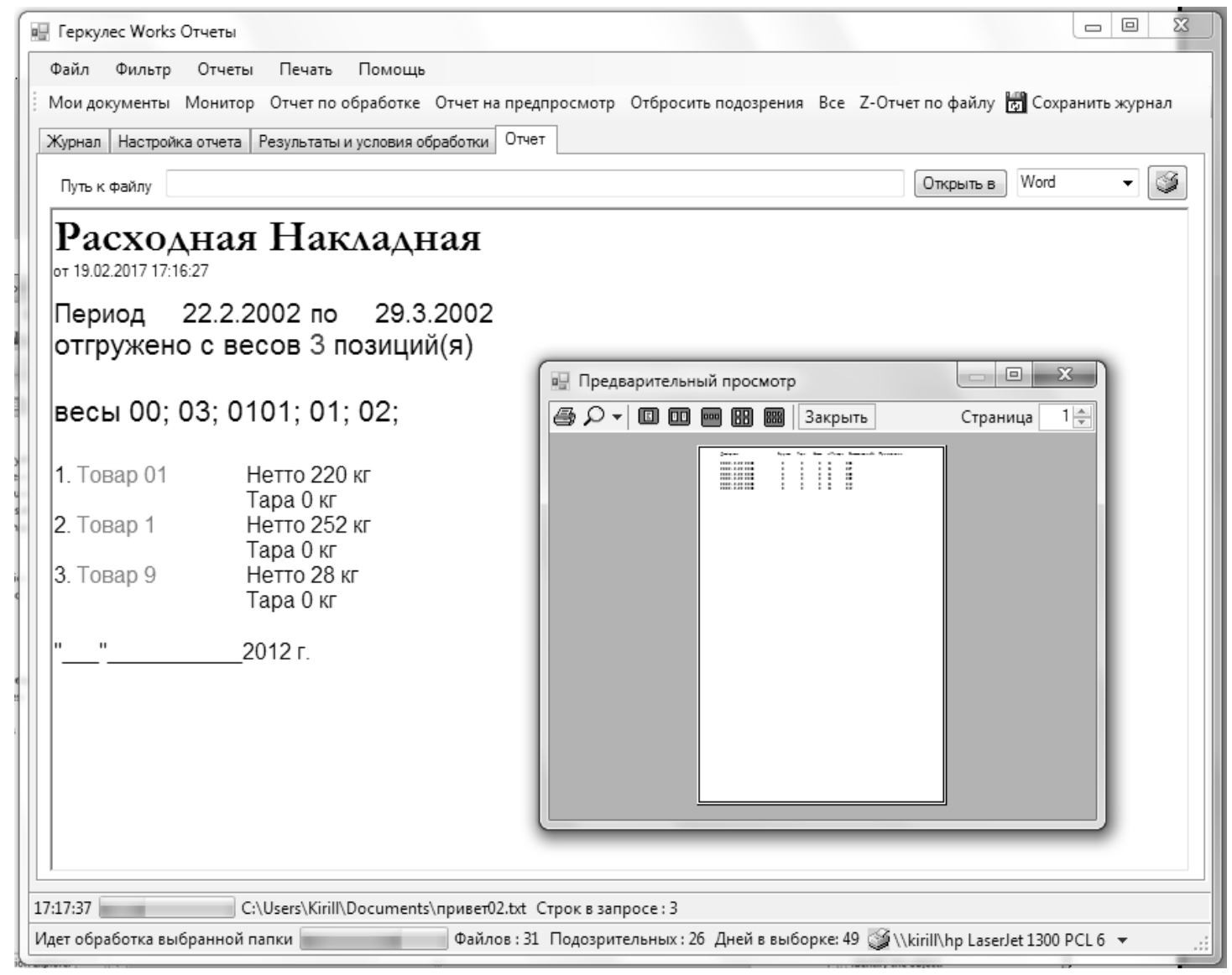

Рис. 14. Предпросмотр Z-отчетов параллельно распечатке форм

цикла вывода результатов запроса; и поле подписи. Bсе доступные поля приводятся в списках слева от поля RTF, который предусматривает расширенные возможности форматирования (рис. 10).

В последнее время требования к срокам разработки программного обеспечения (ПО) значительно выросли, поэтому удобным представляется применить готовый объект RichTextBox для того, чтобы расширить возможности форматирования обычного Memo-поля. «Инкапсуляция» обычного RichTextBox связана с необходимостью обеспечить вывод расширенного форматирования на печать, с выбором из списка доступных принтеров, настройкой их параметров и т.д. В качестве адаптера можно использовать довольно распространенный сейчас class RichTextBoxExtensions[11], а в качестве class-a инкапсулятора RichTextBoxPrintHelper, где полем объекта хранится ссылка на обрабатываемый на печать RichTextBox, без создания объекта наследника.

Для вывода результатов обработки данных и журнала можно адаптировать обычный System.Windows. Forms\ListView.
Однако приходится переопределить методы Drawltem, DrawSubltem, DrawColumnHeader, чтобы ускорить рендеринг при выводе структурированного списка на экран, который усугубляется естественным параллельным выполнением запроса для вкладки результаты и условия обработки, что делает уместным применение здесь распараллеливания и Лямбда-выражений (микро-процессов) С\#.

Следует отметить, что программы на базе компилятора MicroSoft проводят обработку быстро даже на одном ядре. В средах Borland Pascal или Borland C++ раньше требовалось применить здесь объект FileStream или IOStream, для поточного обращения к файлам и файловой системе.

Процесс такого обращения стал теперь унифицирован и работает достаточно быстро даже на одном ядре без дополнительной адаптации. Пополнение базы данных программы Монитор практически не влияет на скорость работы программ, что позволяет запустить и использовать Журнал параллельно на одном ядре. Как ранее замечено, база данных может сильно расти. Механизмы ODBC и OLE работают относительно 


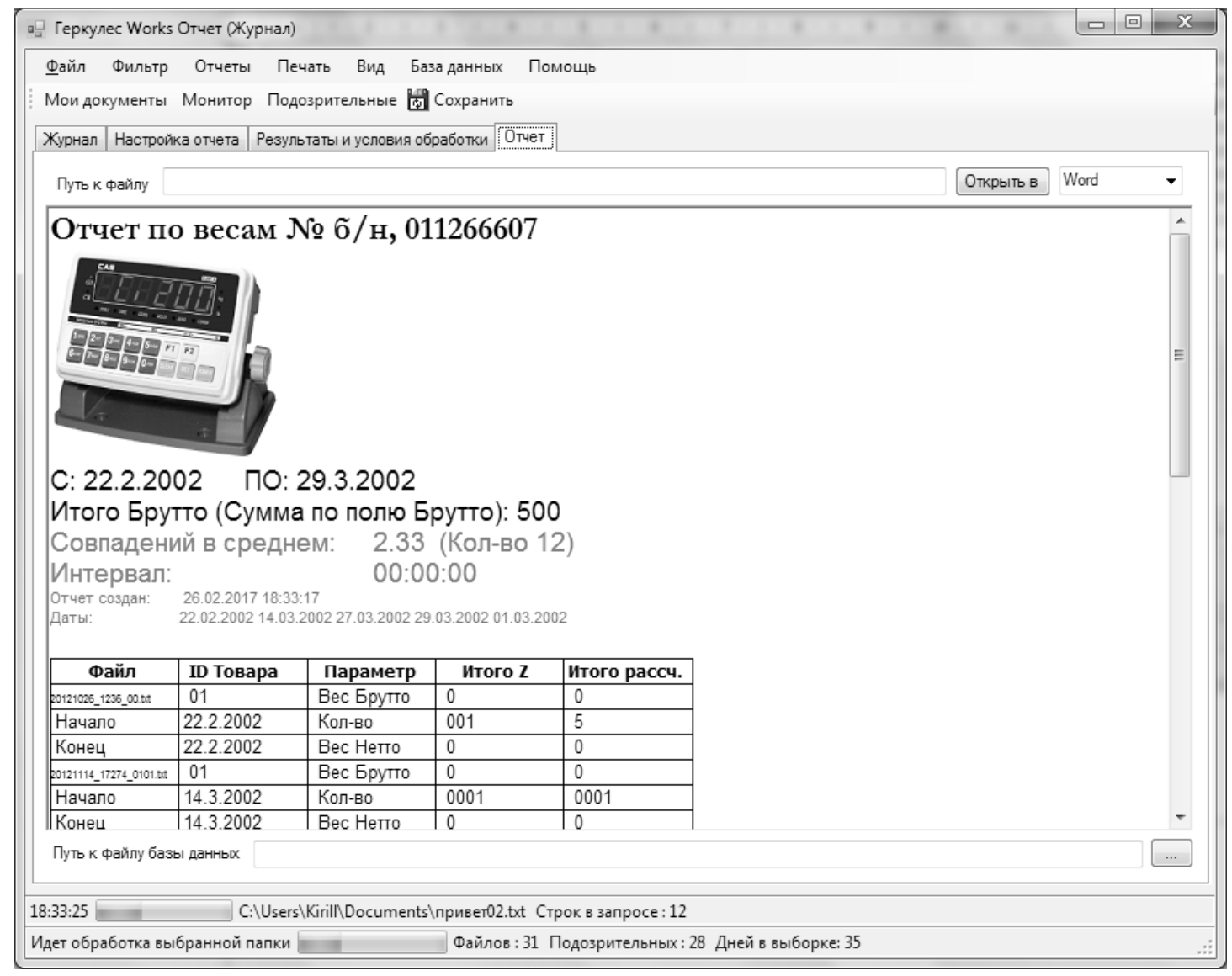

Рис. 15. Отчет с таблицей и расширенным с форматированием

медленно. В процессе выполнения запросов, считывание и дополнение происходит порцией. Поэтому расчет делается на то, что если оконечному потребителю или пользователю не хватит такого генератора отчетов, то он построит запросы и дополнительные отчеты, открыв файл vesy.mdb в MSAccess, или подключив к MSSqIServer.

На стадии разработки реализовано два варианта обработки, в первом варианте выборка полей выполняется автоматически. Фильтрации или дополнению при выводе подлежат лишь отдельные группы, которые можно включить в отчет или форму при желании, таких основных групп - пять. Во втором варианте предусмотрена фильтрация по трем полям, которые можно выбрать из списка всех доступных полей. Обработка происходит параллельно, но в последовательном режиме, т.е. без распараллеливания, чтобы обеспечить четкость при работе с данными, которые могут иметь коммерческое значение, поэтому распараллеливание лучше оставить для параллельного построения запросов.

Отчет на базе генератора отчетов (форм), предусматривающий расширенное форматирование - толь- ко один, а структура вывода разная. Предусмотренные стандартные отчеты позволяют получить «ценники» и протоколы параллельно построению отчета на базе «сводного» запроса.

В отчетах получаемых с первичного преобразователя всего колонок - 5 или 6. А в журнале или отчете их может быть более 10-ти полей: Файл, № , Дата начала, Дата конца, Время начала, Время конца (взвешивания), Нетто, Брутто, Тара, БруттоХ, БруттоZ, CountZ, Совпадний, Количество дублирующих взвешиваний (одинаковых строк) - совпадений, Минимальный интервал, Кодировка (utf8, 1251 и т.д.). DoubleClick открывает непосредственно файл, полученный с весов, соответствующий данной строке журнала.

Обработка данных проходит по принципу построения сводной таблицы, аналогичной MSExcel, но данные подобраны в текстовом формате или лежат в базе данных. В процессе перегруппировки данных происходит постепенное сужение выборки, к оконечному результату которой применяется дополнительный фильтр на базе критериев выбираемых через checkbox, или через указание полей и их значений. 


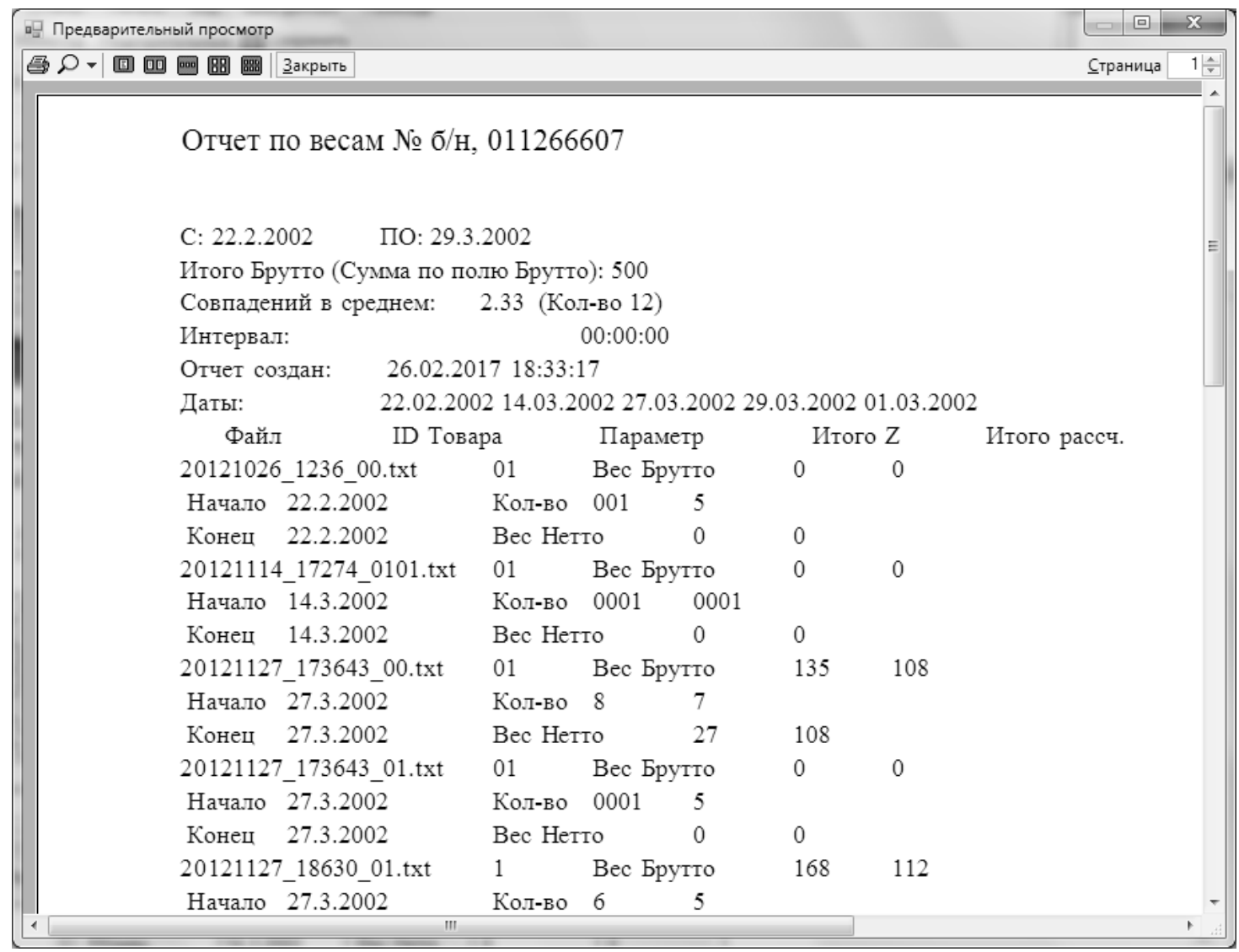

Рис. 16. Таблица в теле отчета без расширенного форматирования

RTF textbox позволяет дать пользователю возможность создать заготовку для оконечного отчета в MSWord или OpenOffice Writer и перенести её в RichTextBox вместе с таблицами и их строчным форматированием, следует правда отделить шапку таблицы и элемент цикла таблицы. Цвета, жирность, подчеркивания, шрифты будут такими же, как в Word или OpenOffice.

Исходный плюс на языке C++ позволяет с перспективой взглянуть на Unix (Qnx) или Linux. А промежуточный код CIL на совместимость с MacOS. В средах Borland такая перспектива была связана с использованием Borland Kylix в «уцнисон» BPW или Delphi.

При необходимости можно вывести отчет в упрощенном виде, чтобы ускорить вывод на матричный принтер, для которого предусмотрен одновременный циклический вывод. Параллельно можно распечатать и полную сводку по журналу, она отображается в усовершенствованном ListView. Перед распечаткой отчета сформированный документ можно подправить прямо в RTFBox.

Использование расширенного форматирования приводит к тому, что информация на печать подготав- ливается в растровом виде, если она содержит логотипы компании или фирмы, специальные изображения и знаки, штрих-коды и предохранительные знаки. Можно сэкономить время на подготовке документа к печати, чтобы ускорить процесс многократной выдачи отчетов, в которых спецформатирование сброшено, и контекст подготовленный к выводу на печать представлен только в текстовом виде. B Borland Pascal или C++ для Windows 3.11 такой контекст имел обычно тип hDC (h - handle, ссылка или номер в потоке или соответствующей коллекции), причем один и тот же контекст можно было использовать как вспомогательный как для вывода в окно или форму, так и на печать. Вывод осуществляется при таком подходе через Graphics Driver Interface GDI (GDI. exe)[9].

Упрощенный вывод предусмотрен не только для отчетов и форм в RTF формате, но и для журнала, включающего полную информацию, так как он может быть длинным. Отчет может быть выполнен в виде «ленты».

Простой вывод на печать можно выполнить в С\# с использованием объекта PrintDocument, совмещенный в ООП с циклом обработки событий (рис. 18). 


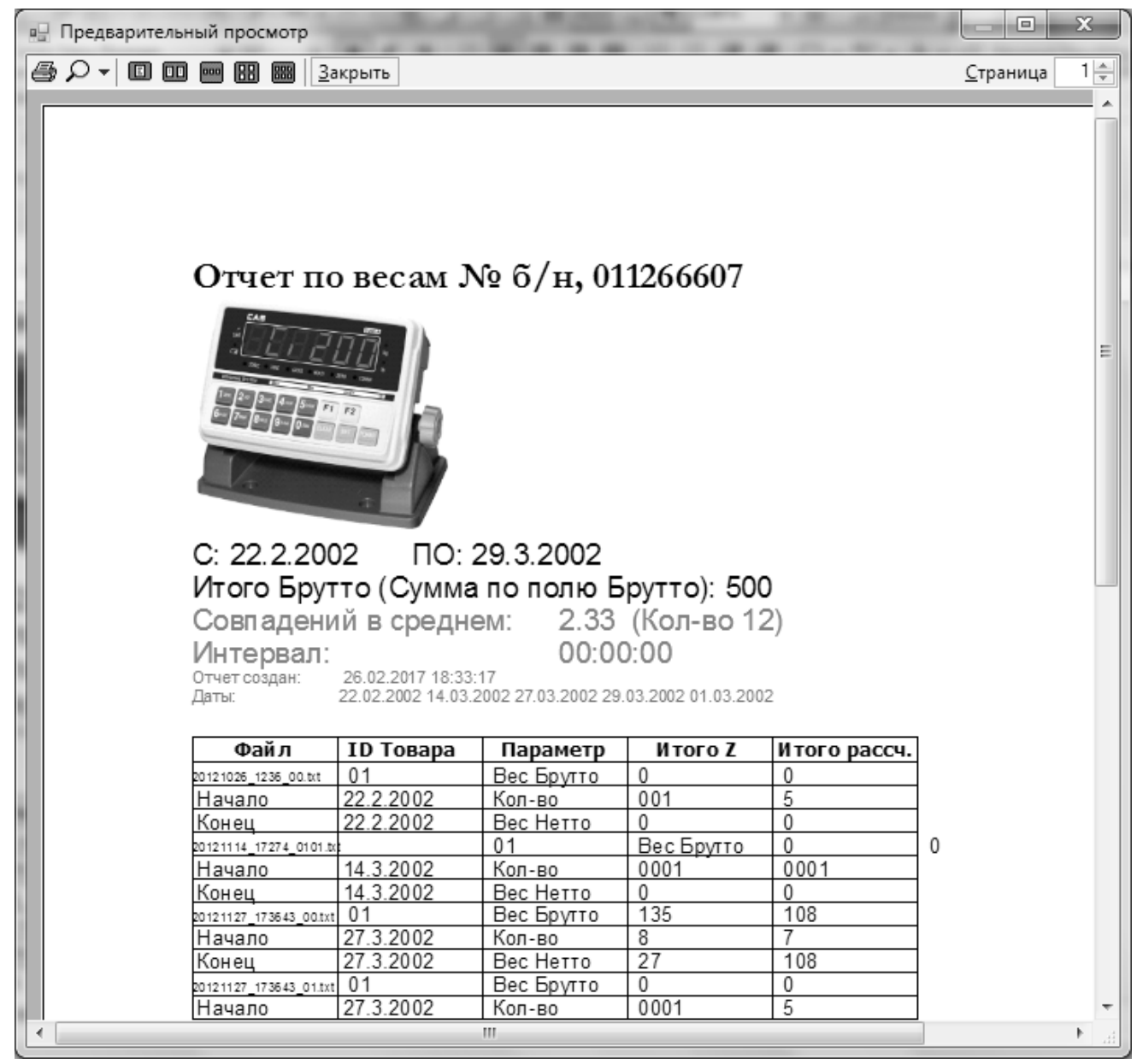

Рис. 17. Предварительный просмотр отчета при выводе на печать

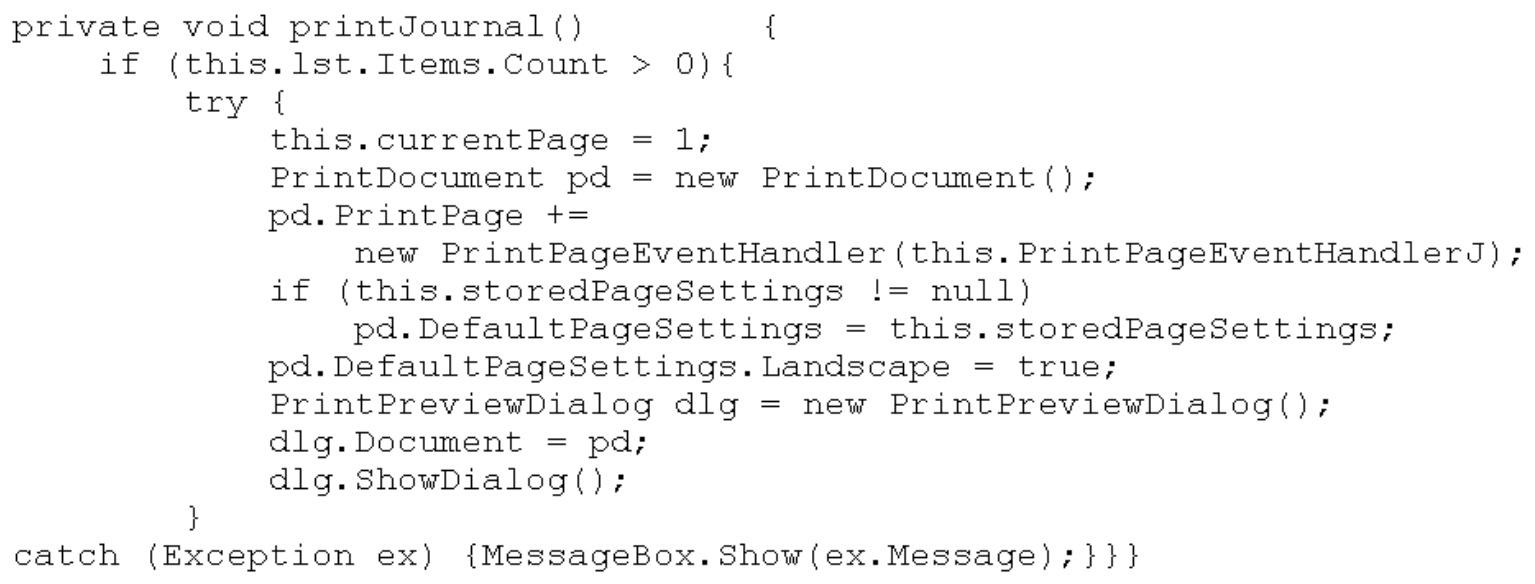

Рис. 18

protected void PrintPageEventHandlero(object obj, PrintPageEventArgs ev)

Рис. 19 

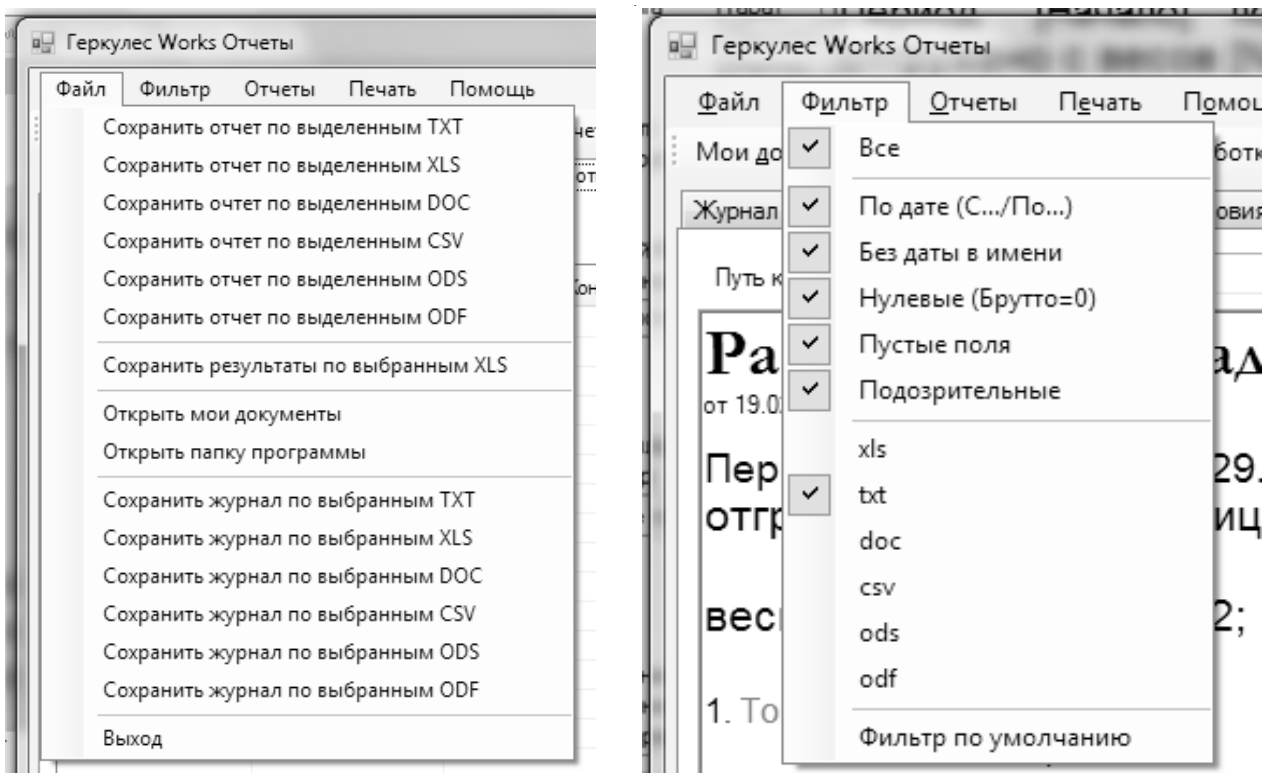

Рис. 20. Меню «Файл» и «Фильтр» программы ГеркулесWorksОтчеты

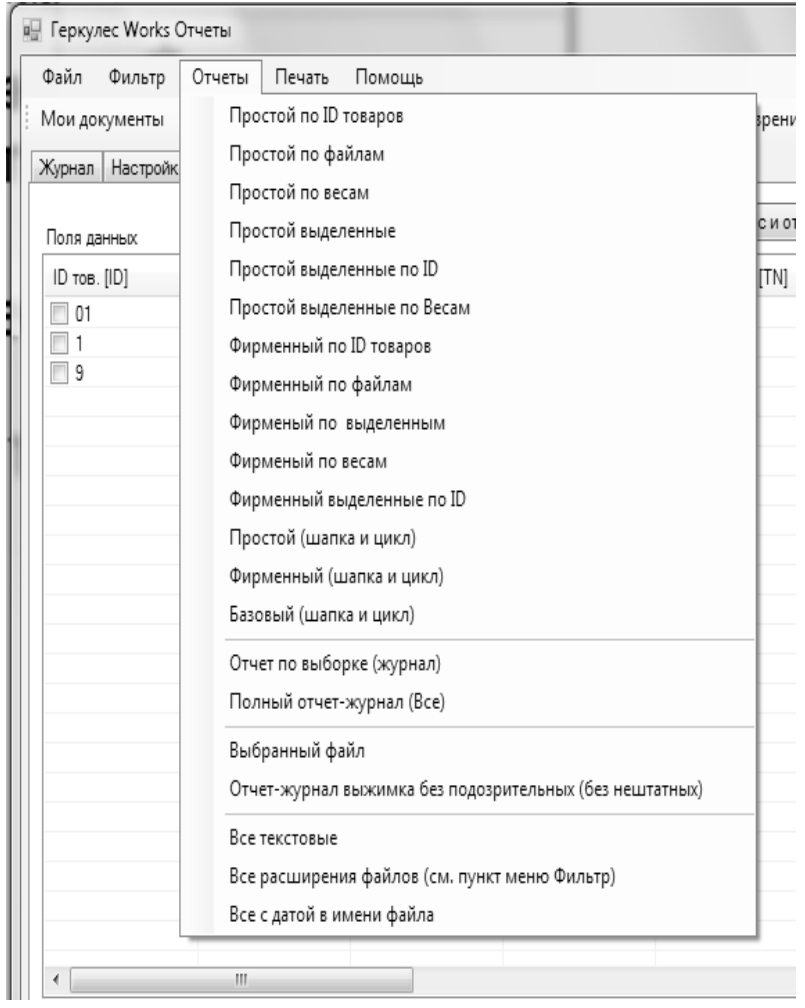

\begin{tabular}{|c|c|}
\hline Печать & Помощь \\
\hline \multicolumn{2}{|r|}{ Предварительный просмотр/печать отчета с оформлением } \\
\hline \multicolumn{2}{|r|}{ Печать отчета с оформлением непосредственно на принтер } \\
\hline \multicolumn{2}{|r|}{ Предварительный просмотр/печать отчета без оформления } \\
\hline \multicolumn{2}{|r|}{ Предпварительный просмотр/печать журнала } \\
\hline \multicolumn{2}{|r|}{ Предварительный просмотр/печать файла Z-отчета } \\
\hline \multicolumn{2}{|c|}{ Настройка принтера } \\
\hline \multicolumn{2}{|c|}{ Предварительный просмотр } \\
\hline & едварительный просмотр/печать шаблона \\
\hline
\end{tabular}

Рис. 21. ГеркулесWorksОтчеты: меню «Отчеты » и «Печать»

Для вывода в контекст используют объект Graphics g = ev.Graphics (GDI+[7]); и для страницы переопределяют метод[8] (рис. 19).

Внутри контекста страницы достаточно осуществлять отрисовку для текста или дополнительной гео- метрии или растровой графики, так же как при выводе через $\mathrm{hDC}$ :

g.DrawString(Izm[0].ToString(), this.mainTextFont, Brushes.Black, 


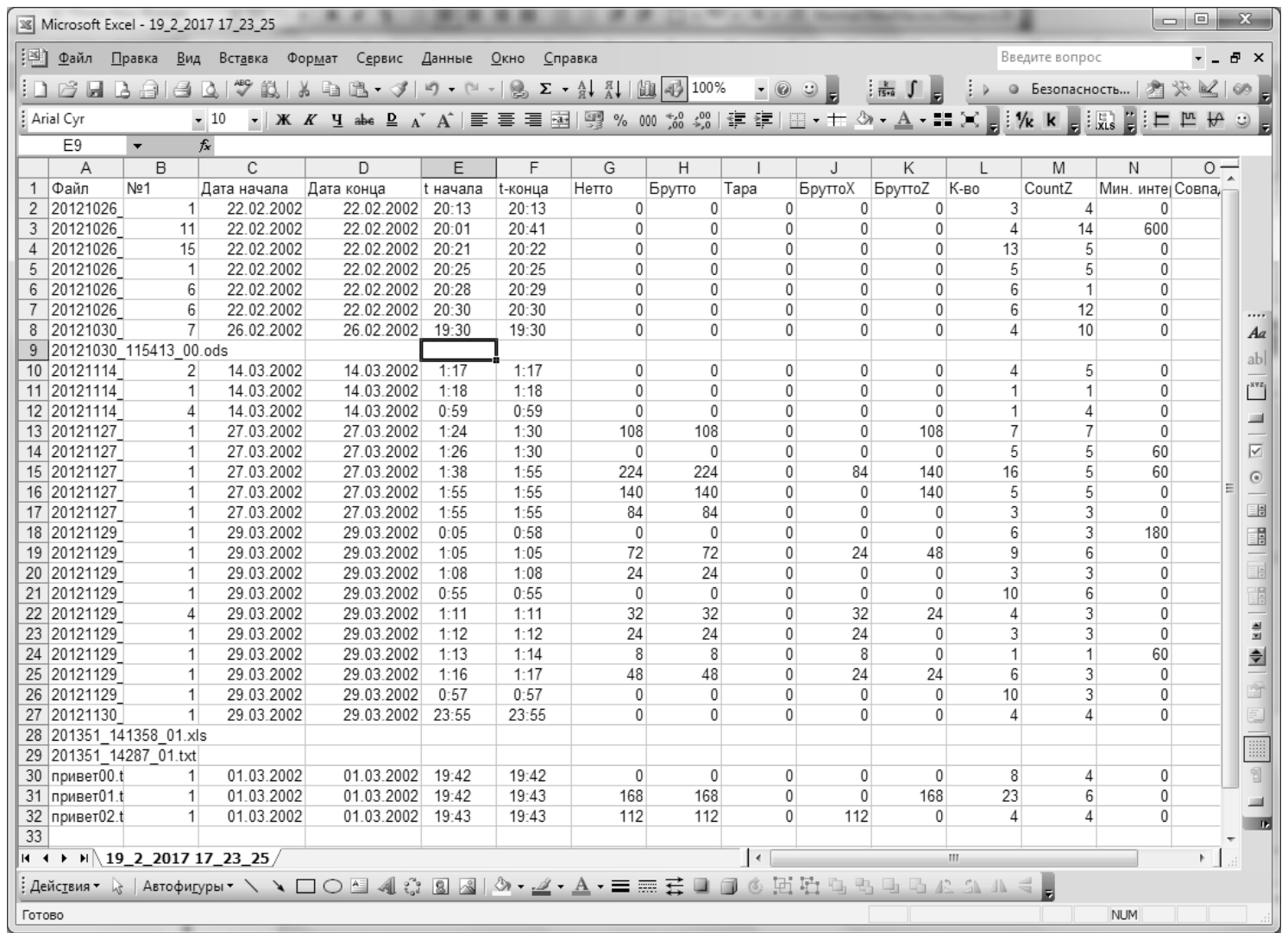

Рис. 22. Экспорт результатов обработки в MSEXcel (xls) или OpenOfficeCalc (CSV)

new Rectangle(50 + offsetX, 10,450+ offsetX, 50)); //180

Для перехода на следующую страницу следует подвергнуть контекст измерению. через некоторую меру например N (максимальное количество строк):

if $(\mathrm{N}==60)$ ev. HasMorePages = true;

После чего счетчик количества страниц наращивают и переводят статус перехода на следующую страницу в исходное состояние.

++ currentPage;

if (currentPage $>$ NP) ev.HasMorePages = false;

\section{Меню и кнопки программы анализа пакетов шиклического опроса}

При работе с данными в текстовом формате имеет смысл положить дубликаты некоторых наиболее важных файлов, которые можно выделить разными форматами файла, и в процессе работы проводить фильтрацию по формату файла через меню. Результаты фильтрации при этом можно сохранить в разных форматах для разных сред. Здесь форматы XLS, DOC, TXT ориенти- рованы на Windows, а CSV, ODS, ODF ориентированны на Linux-подобные операционные системы.

При подготовке шаблонов отчетов можно опереться на готовые заготовки или скопировать их в Word или writer и там подправить, и затем перенести обратно. Для возврата исходных установок не нужно исправлять набранные отметки, достаточно выбрать Check: «Фильтр по умолчанию», а набор настроек пользователя для отбора и фильтрации останется зафиксированным.

Предусмотрен экспорт выборки по журналу в Excel или Calc, что позволяет разбить отчет на страницы так, как больше нравится пользователю.

Программирование в среде С\# TeamEdition - это удобно

Среда разработки предназначена для работы при участии рабочей группы, но программист может работать со средой программирования и разработки индивидуально. Среда может использоваться для разработки как на 32-ух, так и на 64-х битной платформе. Поэтому программы для первичного преобразователя весов могут быть откомпилированы в режиме комбинированной 
совместимости для использования процессоров разной битности.

\section{Использование технологии ADO (Access data objects)}

Среда позволяет таким образом вынести базу данных ADO.net как на сервер, так и подключить её в режиме клиент-сервер. Или использовать Microsoft OLE DB provider для MSSQLServer. Наиболее практичной в смысле применения и быстрой оказывается среда MSSQLServer2000. Также удается применять версии MSSQLServer 2005, 2008, 2010 и др. Хотя их переустановка затруднительна, что делает такие доступные для нас релизы проблематичными для длительной промышленной эксплуатации в непрерывном режиме. Версия 2000 хорошо зарекомендовала себя в длительном непрерывном режиме.

\section{Использование \\ SmartlnstallMaker \\ $\triangle \wedge$ с созАания АИстрибутива}

MicroSoft Visual Studio Install Maker сложно применять даже для не очень сложных конфигураций, поэтому имеет смысл использовать другую программу для создания оконечного дистрибутива, который доходит до оконечного потребителя. В отзывах на программу: «Разработчики из InstallBuilders Company поработали на славу и создали действительно качественный продукт». Процесс создания и набора архива происходит более конкретизировано. В отличие от Visual Studio программист или пользователь сам набирает в дистрибутив необходимые файлы, a Install Maker от MicroSoft компонует весь набор из активного решения.

\section{Зак^ючение}

Срок разработки такого терминала для атрибутизации со средой анализа накапливаемых данных составил 3 месяца, без учета сетевых подключений по протоколу UDP и TCP-IP, т.е. с работой только через СОМ-порт, настройкой форматированных отчетов в формате RTF. Применение технологии ADO.net позволяет объединить данные в общую базу данных, минуя включение приборов в офисную сеть. Тогда расчет можно сделать на то, что каждые весы оснащаются отдельной персональной ЭBM. Свойства объекта RTFTextBox включает методы сохранения и записи содержимого в формате RTF, что приближает программиста к работе с таким форматом, позволяет соотнести его с форматами HTML и XML. Формат RTF позволяет использовать разные кодировки и включить информацию о них и о дополнительном форматировании в тело оконечного документа: отчета, формы; или исходного z- или х-отчета.
Рассмотрение вопросов связанных с использование графических контекстов важно для начинающих программистов в связи с тем, что среды использовавшиеся до 2000 года были реализованы ещё на базе ООП предназначенного для 1-го ядра Windows 3.11-WinMe. Например могут быть исходные тексты PCAD2002-2004 (ООП-classic), которые использовались как раз на таких относительно старых платформах, но можно использовать и на современной платформе х64. Такое рассмотрение придает общий взгляд на унифицированную структуру объекта и/или соответствующего ему класса, как с точки зрения программирования на классах, так и с точки зрения классического объектно-ориентированного программирования (ООП). Здесь можно обратить внимание на то, что многие используемые сейчас вспомогательные приборы, такие как настенные сканеры штрих-кода, весы, каталоги, всё ещё ориентированы на использование Windows 3.11 Embedded, Win98 и др., программирование для которых базируется на классическом ООП.

Обработка больших объемов атрибутированных данных требует применения параллельных и поточных технологий на базе современного ООП, с которыми вполне конкурируют старые технологии DMA и Stream для одноядерных терминалов, оба подхода со своими разными достоинствами. Оформление потоков Stream, визуализация, систематизация при распараллеливании требуется наследование и разработка новых эффективных классов и атомов по сравнению с медленными предлагаемыми готовыми, которые не подходят для баз размером более 70-100Мбайт. Атрибутизация и выборки требуют максимальной производительности, что решено давно ещё на уровне потоков в MS-DOS. Аналогичные потоки доступны и в более ранних версиях Visual Studio C\#. Доработка приложений снаружи позволяет предложить двух и много вариантное отображение форм, поэтому обе части классическое ООП и современное ООП - интересны для достижения следующего уровня производительности по сравнению с использованием наполненных потоков DOS, и стали коммерчески востребованы больше чем программирование на низком уровне, где предусмотрено асинхронное выполнение. Применение Java можно предполагать для весов c Web-интерфейсом, чтобы сделать их интересными с точки зрения анализа процесса выносимые интерфейсы предварительно прорабатывают двояко.

Разработка программного обеспечения (ПО) учета широкая область разработки. Опыт создания и разработки: программ для коммерческого учета газа и других рабочих сред; ПО баз данных складского и бухгалтерского учета можно применить в процессе разработки ПО и средств массового учета с использованием весов. 


\section{ЛИТЕРАТУРА}

1. Волошиновский К. И. Геркулес Works-Монитор (Весы) на языке С\#. Авт. СВ. на программу для ЭВМ № 2016611243 0т 28.01.2016. — 58 с.

2. Волошиновский К. И. Геркулес Works-Отчеты/Журнал (Весы) на языке С\#. Авт. Св. № 2016611342 от 01.02 .2016 г.— 40 с.

3. Волошиновский К. И. Viewer текстовых файлов, аналог MSWord на языке программирования С\#. Авт. Св. № 2012615699 от 22.06 .2012 г. 一 52 с.

4. Волошиновский К. И. Программный комплекс SEVC91/7188. (С++). Авт. Св. № 2010614884 - . от 27.07.2010 г. — 40 c.

5. Волошиновский К. И. Программа для макетно-отладочной платы EB552 с модулями-драйверами для порта RS232, шины I2C, часов PCF8583, EEPROM, AТ24С64, ЖКИ, электронного корректора Sevc-91 и модулем описания портов Atmel (Intel)-совместимого 8-битного процессора. Авт. св. № 2012615700 от 22.07.2012-25 c.

6. Волошиновский К. И. Система управления документами аналог Windows Commander на языке Borland Pascal for Windows. Aвт. св. № 2012616552 от 20.07.2012-67 c.

7. Official Course. C\#.Net M2555A. MicroSoft Co. Volume 1. 2002. - $208 \mathrm{c}$.

8. Official Course. C\#.Net M2555A. MicroSoft Co. Volume 2. 2002-296 c.

9. Федоров А., Рогаткин Д. Borland Pascal в среде Windows. Киев: «Диалектика». 1993 г._ 656 с.

10. Borland Pascal: практическое использование Turbo Vision 2.0 / А. Федоров.—Киев: Диалектика, 1993. — 272 с.

11. http://msdn.microsoft.com/en-us/library/ms996492.aspx

12. Волошиновский К. И. Развертка осциллограмм для теплового и миллиметрового канала с подбокой в виде базы данных (С\#). Авт. Св. № 2016612782 0т 11.01.2016-25 c.

(с) Волошиновский Кирилл Иванович ( gas7dev@gmail.com )

Журнал «Современная наука: актуальные проблемы теории и практики»

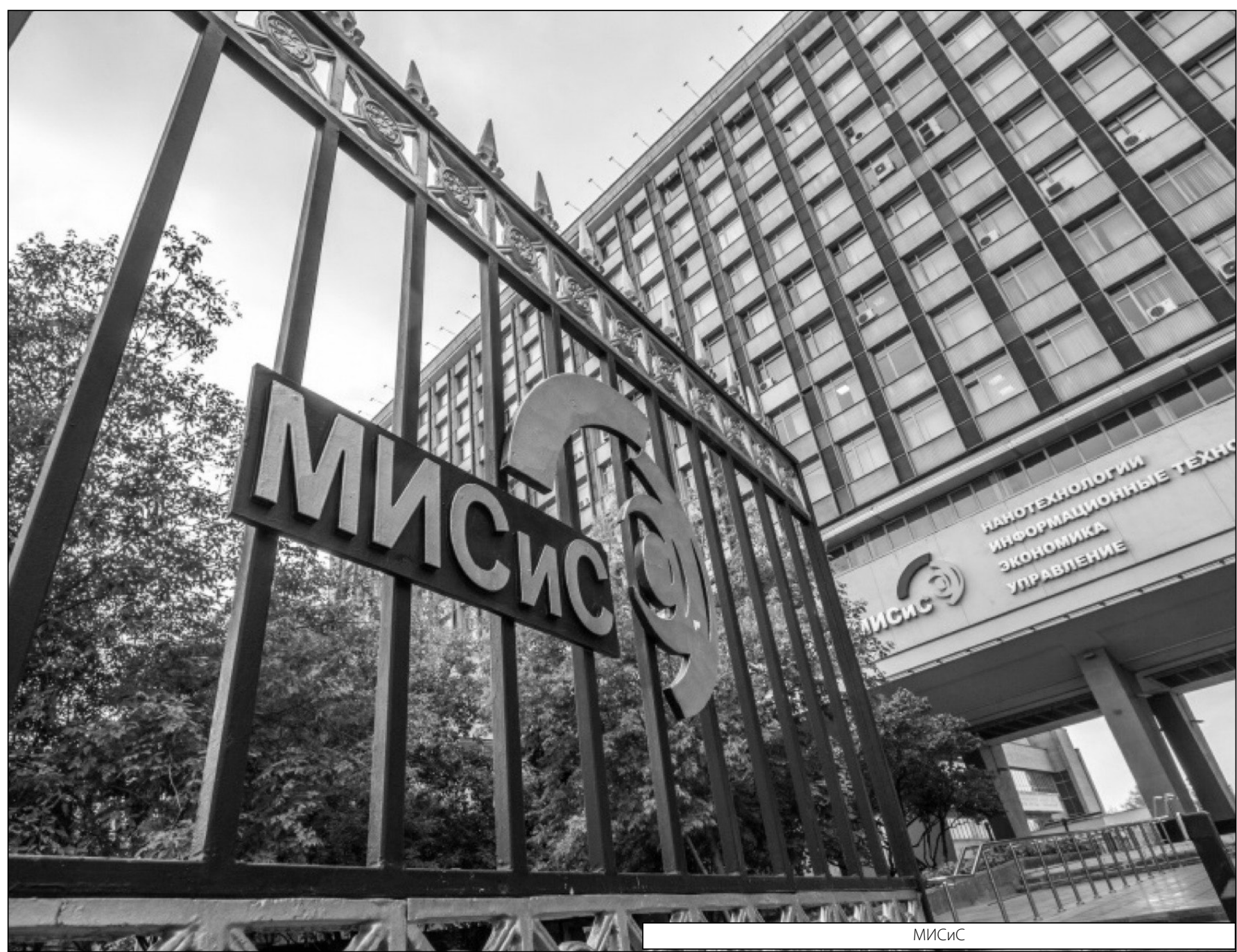

